DOE/ID/13103 - -T2

LASER-PRODUCED PLASMA SENSOR-PROBE SYSTEM FOR IN SITU MOLTEN METAL ANALYSIS

Final Technical Report

Y. W. Kim

PFP. PIV

APR 241997

January 1997

OSTI

Work Performed Under Contract No. FC07-91ID13103

For

U.S. Department of Energy

Assistant Secretary for

Energy Efficiency and Renewable Energy

Washington, DC

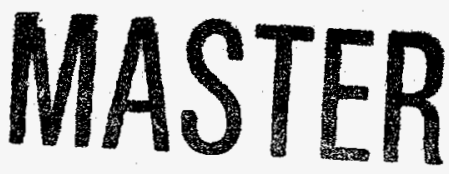

OISTRIBUTION OF THIS DOCUMENT IS UNLIMITED

By

Lehigh University

Bethlehem, PA 
DOE/TD/13103

Distribution Category UC-1400

\title{
LASER-PRODUCED PLASMA SENSOR-PROBE SYSTEM FOR IN SITU MOLTEN METAL ANALYSIS \\ Final Technical Report
}

Y. W. Kim

January 1997

Work Performed Under Contract No. FC07-91ID13103

\author{
Prepared for the \\ U.S. Department of Energy \\ Assistant Secretary for \\ Energy Efficiency and Renewable Energy \\ Washington, DC \\ Prepared by \\ Department of Physics \\ Lehigh University \\ Bethlehem, PA 18015
}




\section{DISCLAIMER}

This report was prepared as an account of work sponsored by an agency of the United States Government. Neither the United States Government nor any agency thereof, nor any of their employees, make any warranty, express or implied, or assumes any legal liability or responsibility for the accuracy, completeness, or usefulness of any information, apparatus, product, or process disclosed, or represents that its use would not infringe privately owned rights. Reference herein to any specific commercial product, process, or service by trade name, trademark, manufacturer, or otherwise does not necessarily constitute or imply its endorsement, recommendation, or favoring by the United States Government or any agency thereof. The views and opinions of authors expressed herein do not necessarily state or reflect those of the United States Government or any agency thereof. 


\section{DISClamier}

Portions of this document may be illegible in electronic image products. Images are produced from the best available original document. 
Final Technical Report

Laser-Produced Plasma Sensor-Probe System

for In-Situ Molten Metal Analysis*

(Agreement Number DE-FC07-91ID13103)

\author{
prepared by \\ Yong W. Kim \\ Department of Physics \\ Lehigh University, Bethlehem, PA 18015
}

for

U.S. Department of Energy

Office of Industrial Technologies

28 January 1997 


\section{Executive Summary}

The radically new methodology of in-situ laser-produced plasma (IPP) analysis of molten metals, as developed at Lehigh University, has been implemented into an LPP sensor-probe system, ready for deployment at steelmaking facilities. The system consists of an LPP sensor-probe head, which is immersed into the molten metal bath for the short duration of measurement, a control console, an umbilical cord connecting the above two units, and a support console providing coolants and pneumatic supports to the control console.

The Department of Energy funding has supported Phase III-A and $-B$ of the project in a joint sponsorship with AISI, CTU 5-2 Consortium, and Lehigh University. The objectives have been to: i) implement the molten metal calibration protocol for the LPP analysis methodology; ii) implement the methodology in the form of a second-generation LPP sensor-probe system, which facilitates real-time process control by in-situ determination of elemental composition of molten steel alloys; iii) deploy such developmental systems in steelmaking facilities; iv) upgrade the systems to a third-generation design; and $v$ ) effect technology transfer by selecting a manufacturer of commercial LPP sensor-probe systems.

Four of the five objectives have been fully met. The deployment objective has been partially realized at present. The full LPP sensor-probe system has been put through trial immersion runs at a foundry, but its deployment at steelmaking facilities has progressed to a stage where various issues of financial and legal nature are being codified into a formal agreement between a host site and Lehigh University.

The technical issues of a field deployment of the LPP sensor-probe system include systematic analysis of the manufacturing process parameters, site preparation, consisting of design and fabrication of an appropriate manipulator of the LPP sensor-probe head, and installation of the system in the host facility. There emerged several major new requirements for the system from the operators of the host site facilities and in the course of the technology transfer process. These have been fully accommodated, resulting in a number of significant design modifications and addition of several new measurement capabilities.

As part of the technology transfer process Lehigh University has entered into an exclusive licensing agreement with Bailey Engineers, Inc., as the designated manufacturer of the LPP sensor-probe system for steelmaking applications in the territory of the North American continent. The transfer of the technology and design specifications will be completed once Bailey Engineers has exercised the provisions of the agreement following the first full deployment of the LPP sensor-probe system. 
Table of Contents

page

Executive Summary 2

Table of Contents 3

List of Figures 4

List of Tables 5

I. INTRODUCTION 6

II. THE LASER-PRODUCED PLASMA SENSOR-
PROBE SYSTEM (LPPSPS)

1. A Narrative Overview 9

2. Design Specifications 12

III. SUMMARY OF SCIENTIFIC MILESTONE TASKS 26

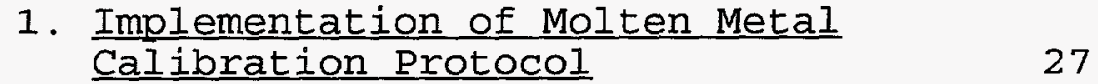

2. $\frac{\text { Considerations of the Analysis }}{\text { Precision }} \quad 39$

3. Performance of Immersion Tube

4. Hardware Integration 42

5. Software Integration 43

6. Adaptation to Shop-Specific

7. Self Repair and Adjustment 46

8. Mechanical, Thermal, and 46

IV. ISSUES ASSOCIATED WITH FIELD DEPLOYMENT OF LPPSP SYSTEM 47

1. New Requirements 47

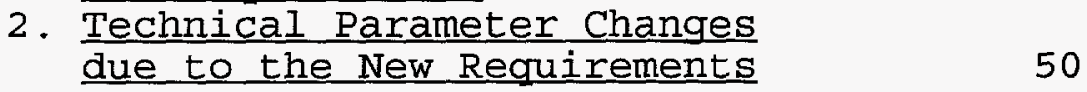

V. TECHNOLOGY TRANSFER ISSUES 51

VI. CONCLUSIONS 51

Acknowledgement 53 


\section{List of Figures}

Fig. 1. LPPSP events diagram for double

page

measurement mode.

Fig. 2. The normalized time of heating to the onset of melting as a function of normalized values for specimen diameter, electrical resisitivity, thermal conductivity and specific heat. The reference point of normalization is indicated where both the ordinate and abscissa read unity and the specimen diameter is 1/4". only one physical parameter is changed at a time to calculate the factor by which the time of heating is changed, as shown. The RF heater power is kept at a constant level for all calculations.

Fig. 3. Schematic diagram of the impulse transducer, as mounted at the base of the specimen holder. Normally, a specimen of 1/4" diameter and 2" length is mounted at the top. The specimen holder is inserted into the RF levitator/heater through a vacuum feedthrough, placing the top of the specimen within the RF levitor/heater coil, just below the point of the magnetic field minimum.

Fig. 4. Calibration of the impulse transducer against the measured impact of a falling steel sphere.

Fig. 5. Impulse transducer output for five successive IPP runs on a solid copper target. The sequence of the runs goes from the bottom to the top. The vertical deflection is in arbitrary units. The sharp spikes appearing at the outset are due to the switching noise of the high power pulsed laser.

Fig. 6. Impulse signals for four molten SS316 specimens. The vertical deflection is given in arbitray units. The sharp spikes appearing at the outset are due to the switching noise of the high power pulsed laser. Four different specimens were brought to melting individually starting from room temperature. A signal processing was applied to the transducer output to remove a large periodic RF heater noise. 


\section{List of Tables}

page

Table 1. Dynamic Range of Active Vaxiables

10

Table 2. Summary of the molten metal calibration data 


\section{INTRODUCTION}

The metal producing industry has for some time been facing the great challenge of increasing productivity by reducing costs and extending the useful life of existing equipment with mixed success. In a detailed study of sensor needs within the steel industry, the American Iron and Steel Institute (AISI) determined that rapid in-process analysis of molten metal was one of four sensors critically needed to reduce costs and increase productivity. Lehigh University has been spearheading this undertaking with partial support under the financial assistance program of the U.S. Department of Energy Metals Initative. It is quite evident that successful development of a composition sensor for steel would find broad applications with other materials producers.

Steelmaking involves the basic steps of charging the furnace, melting the charge, and refining. During refining, it is critical that the operating parameters be adjusted and controlled so the chemistry of the melt is within predetermined units. To take a sample from an operating furnace and have it analyzed is time consuming and often accounts for as much as $20 \%$ of the overall time required to refine a heat of steel. Under the most ideal conditions, total sampling and analysis time takes up to 5 minutes.

According to the AISI CTU 5-2 task force reports, 1,2 development of equipment for the rapid in-process analysis of molten metal has the potential to provide at least $\$ 200$ million 
annually in tangible benefits to the steel industry alone. The tangible benefits include:

reduction in heat time;

increase in refractory life;

reduction in material costs;

reduction in desulfurization costs; and

reduced variations in hot metal composition.

In addition to the tangible benefits, the use of in-process

analysis of molten metal can provide intangible benefits:

improved product quality and productivity;

speeding up ladle metallurgy processes;

eliminating major capital investments;

improved basic understanding of steelmaking process; and

reducing inventory by closer control of manufacturing.

There are numerous applications for such in-process analysis

in steelmaking and some of them are to:

- provide iron composition continuously during furnace cast,

- provide rapid analysis of steel bath during refining,

- monitor sulfur removal during desulfurization,

- assure meeting of requirements for ladle treatment,

- optimize trim additions in the ladle,

- make ladle tests while ingot teeming,

- monitor metal composition in continuous caster, and to

- optimize alloy additions in vacuum degassing.

The AISI CTU 5-2 task force reports and Lehigh's own industry assessment identify the two primary areas of application: i) 
steelmaking for high-performance high-alloy steel applications and large volume low-alloy production within the existing manufacturing shops; ii) direct steelmaking for both low and high alloys in an integrated manufacturing environment. The first area of application is immediate and the second lies sometime in the future as several current initiatives for integration in the industry undergo development.

The above considerations hold true for other metals industry such as aluminum, copper and refractory metals. Of growing significance in recent years are the areas of waste disposal by thermal decomposition within a steel furnace as a reactor. This applies to industrial and medical wastes as well as the vast reserves of radioactive wastes. In-situ real-time composition analysis is of great importance in these applications because human access to the reactor is hazardous and timely assessment of the reactor contents is essential to maintenance of the yield and long-term stability of the reaction process.

The research project at Lehigh University on molten metal analysis by laser produced plasmas came to being in 1985 , in a direct response to industrywide needs. The broad objective of this research project has been to develop and implement instrumentation and equipment for rapid in-process analysis of molten metal in metals production shops by means of time-resolved spectroscopic analysis of a laser-produced plasma (IPP) from the molten metal surface. The research project has been structured in three major phases: Phase I. Laboratory verification of the basic 
concept; Phase II. Critical comparison of the new LPP method with the conventional analysis method for solid specimens and field trials of a prototype sensor-probe in small-scale metal shops; Phase III. Design, production and installation of two sensor-probes in metal production shops. It was at the start of the last phase of the project that the U.S. Department of Energy first began to play the sponsorship role in september 1991.

In this report we will summarize the technical accomplishment of the project, resulting in two fully developed hardware systems. The design and makeup of the laser-produced plasma sensor-probe (LPPSP) systems will be described. Their performance in terms of composition analysis precision and robustness will be presented. Detailed accounts of the issues associated with the factory site preparation and implementation for the LPPSP systems will also be given.

II. THE LASER-PRODUCED PLASMA SENSOR-PROBE SYSTEM (LPPSPS)

\section{A Narrative Overview}

Quantitative molten metal analysis by in-situ time- and space-resolved spectroscopy of a laser produced plasma plume from the molten metal surface is a radically new technology, invented and perfected at Lehigh University. This has now been implemented into an LPP sensor-probe system as a real-time in-situ process control tool for metals manufacturing. The environmental conditions vary widely, and the dynamic range of many active variables is summarized in Table 1. 
Table 1. Dynamic Range of Active Variables

\author{
Temperature: $80-3680^{\circ} \mathrm{F}$ \\ Pressure: vacuum - $1.5 \mathrm{~atm}$ \\ Gas composition: inert gas to dirty air \\ Gas velocity: $0-50 \mathrm{ft}$ per sec \\ Surface properties: clean metal \\ to slag covered \\ Absorption at laser wavelength: $2-70 \%$ \\ Alloy composition: extremely widely \\ varied with 10 to 25 or more elements
}

The LPP sensor-probe system is composed of a sensor-probe head unit, control console, hermetically sealed umbilical cord connecting the two, and a support console. The instrumentation has been designed to function over an open-air furnace as well as inside a vacuum furnace. Normally, the LPPSP head is immersed in a molten metal bath past the slag layer at a pre-selected speed. The molten metal is then aspirated into the immersion tube. When a representative molten metal surface is detected by a rangefinder at a pre-set distance, a giant laser pulse is triggered and a dense, high-temperature plasma plume is produced from the surface. The full emission spectrum from the LPP plume is measured during a sub-microsecond period at a pre-set time interval after the laser pulse. The spectral data are interpreted by dedicated computers, and the elemental composition of the molten metal is determined. The sensor-probe head is then withdrawn from the bath. The entire 
sequence of events takes less than one minute.

The mode of deployment of the LPPSP system and its utilization depend on the particular way a steelmaking facility is organized and managed. Characterization of such a host site environment and attendant site preparation for the LPPSP system constitute a significant part of the deployment process.

Two generations of the LPP sensor-probe system have been constructed, and the third, final generation design and instrumentation is nearly completed. The system is capable of simultaneous multi-element analysis. There appears to be no intrinsic limitation to the number of elements that can be analyzed at any one time. Each element must be calibrated for analysis, meaning that, in time, the system can be configured for any set of elements. The third generation design facilitates a simultaneous 25-plus element analysis and includes the capability for self maintenance of the calibration and self repair.

The LPPSP head contains all critical components needed to produce the LPP plume, acquire the spectral data, and manage the immersion and withrawal process. These high-precision, state of the art components are protected by an actively cooled, hermetically sealed housing of integrated multi-skinned shell structure. The immersion tube, attached at the front end of the shell, is protected by a refractory sheath covering both sides of the tube. The protective shell is partitioned into sections for cooling by water and cryogenic gases. The head has additional instrumentation for pneumatic control, onset of immersion 
detection, temperature measurement and calibration maintenance. The umbilical cord connects the LPPSP head to the control console with three dedicated computers and myriads of control electronics. Support services are organized into the support console.

The LPPSP system is made functional by a complex set of software for sensor-probe control and signal processing. It also handles preventive maintenance of the LPPSP system and self repair. These software functions are implemented in software modules. The speed of execution is of primary importance in the context of real-time analysis. The full integration of the software modules is guided by the considerations of adaptation to shop- and process-specific requirements at the host site.

Engagement of the LPPSP system with a molten metal bath requires a remotely controllable manipulator. Installation of a functioning manipulator at a selected steelmaking facility requires substantial efforts as part of the deployment process. It must not only provide the necessary multi-axis movements to the sensor-probe head for the immersion and withdrawal operations, but also be equipped to respond to wide ranging factory situations that may be damaging to the sensor-probe head. Further, limitations imposed by the host site may affect the functionality of the LPPSP system.

2. Design Specifications

\section{A. IPP sensor-probe head}

i) Laser - Na:glass laser which is flashlamp-pumped and Q-switched for sufficiently large single pulse energies. The 
laser can be fired twice within one second in the double measurement mode. This allows two full LPP analysis runs during one immersion of the LPPSP head in the molten metal bath. The double measurement capability is incorporated in the third-generation LPPSP system.

ii) Rangefinder - The arrival of the clean molten metal surface at a predetermined distance from the laser is detected dynamically as the molten metal is either aspirated upward into the interior of the immersion tube or expelled out of the tube. A special purpose rangefinder tracks the movement of the molten metal surface, and its transducer output is digitized and interpreted by one of the three PCs acting as the process control computer. When the threshold condition is met, a command is issued to fire the laser. The same trigger pulse is used to issue several different time-delayed commands. The rangefinder's overall response time is less than one millisecond.

iii) Optics block - All of the optics involved in the delivery of the giant laser pulse, rangefinder, optical pyrometer, and spectroscopic measurements of the LPP plume emissions are incorporated into one optics block. As such, the optics block helps implement an integration of disparate components to achieve the necessary space-time resolution of the LPP emissions in relationship to the laser pulse delivery. The outcome is the high degree of reproducibility of the detected spectral intensities.

iv) Spectrographs - Two independent spectrographs of our own patented design and fabrication are incorporated within the 
sensor-probe head. The dipersive elements are high resolution diffraction gratings. All reflective optics are employed, making them useful down to $1800 \AA$ in the uv range. The linear dispersion is such that, when coupled with photodiode array detectors, spectral resolution of $0.1 \AA$ per detector pixel can be achieved. Yet, the spectral range of more than $4000 \AA$ can be covered at one time by means of the patented segmented mirrors.

v) 2-D array detectors - Photodiode array detectors are used in conjuction with the high-resolution, wide-spectral range spectrographs for measurement of the LPP plume's spectral emission intensities. The arrays are two dimensional, each consisting of more than one quarter of a million detector elements. Each detector array is equipped with an intensifier, which also acts as a timed, gated-exposure device for the detector elements. The detector outputs are in a digital format so that the spectral data can be collected directly onto a dedicated computer. The silicon photodiode detector elements are cooled thermoelectrically in order to maximize the signal-to-noise ratio.

vi) Optical pyrometer - A sensitive, broad-band optical detector measures the radiant flux from the molten metal surface. Its output is digitized and acquired into the process control computer immediately after the firing of the giant laser pulse. The output signal is calibrated against an equivalent radiant source of known temperature.

vii) Pneumatic controller - The process of penetrating the slag layer covering the molten metal and subsequent aspiration and 
expulsion of the molten metal in the immersion tube is orchestrated by controlling the flow of an inert gas inside the immersion tube. The computer, which is designated for process control, oversees the sequencing of the pneumatic controller in relationship to other real-time transducers and delay generators. viii) Dual-zone cooling - The cooling of the protective shell structure is broken up into two zones. The main structure is cooled by high-pressure water flow, while the immersion tube at the bottom of the LPPSP head is cooled by the flow of cryogenically-cooled nitrogen. The cooling flows are boosted in bursts during the short period of each immersion run. Both the gas and water flowing through the LPPSP head originate from, and terminate at, the control console through an umbilical cord. The umbilical cord may be up to fifty feet in length. A support console provides the coolant gases to the control console. All parts of the LPPSP head that penetrate the molten metal surface are kept free of water under this dual-zone cooling arrangement; this eliminates even the remotest possibility of a steam explosion should the coolant leak from the immersion tube.

ix) Refractory sheath - The immersion tube is encased within a refractory sheath over its entire length. In addition, the interior surface is also protected by another refractory sheath. Together, these sheaths form a leak-tight annular container within which the stainless-steel frame of the immersion tube remains encased. The particular refractory material used for this purpose meets the two requirements that it be thermal shock resistant and 
non-wetting. The entire sheath assembly consists of precision-machined, tightly interlocking, axysymmetric pieces. The refractory sheath can endure a large number of immersions without deterioration and does not require clean up or priming between successive immersions.

$\mathrm{x})$ Heat shield for the protective shell structure - In the event that the LPPSP head is projected into a steelmaking furnace or an $A O D$ vessel, in contrast to an open molten metal ladle, the additional heat flux incident on the protective shell structure can be reduced by means of an additional thermal radiation shield. A variation is to implement the heat shield as a permanent part of the furnace roof, which is to be actively cooled by a high-pressure water flow. The LPPSP head would then be move in and out of the furnace within such a shield tube for a measurement run.

\section{B. Umbilical cord}

The LPPSP head is connected to the control console through an umbilical cord, that may be up 50 feet in length. The umbilical cord consists of a flexible stainless steel bellows hose, 2.5" in diameter, and the following cables and tubings contained within: two 25-wire cables; fifteen coaxial cables; four doubly-insulated high-voltage cables; four high-pressure water hoses; four pneumatic control gas tubings; two metallic bellows hoses for cryogenic gas coolant; and coolant gas tubing for the umbilical cord. In addition, the umbilical cord is encased within an electrically insulating tubing. Another layer of ceramic fiber 
cloth is applied to the exerior of the umbilical cord as a thermal shield against the radiant heat flux from the molten metal bath. In the case of an $A O D$ vessel or a molten metal furnace application, the umbilical cord is coiled within a water cooled tubular thermal shield. The LPPSP head then moves within the shield for each engagement with the molten metal bath.

The umbilical cord is the only linkage between the LPPSP head and the external world. All support and command services and two-way data communications orignate from the control console. Maintaining of its integrity is as vital as the survival of the LPPSP head.

\section{Control console}

The control console contains the following major components: three high speed personal computers; a high voltage power supply; storage capacitor banks; three high-voltage trigger pulse generators; two multi-channel time delay generators; signal conditioning electronics for pyrometer and rangefinder; pneumatic controller system; spectroscopic detector controllers; power sources for the LPPSP head; flow controllers for coolant gases and liquids; and assortment of sensors and actuators. One computer is fully devoted to the control and management functions of the LPPSP head, including the immersion operation, rangefinding, triggering of the high-energy pulsed lasers and communications with the outside world. The two other computers are completely dedicated to spectral data aquisition and analysis of the data for rapid determination of the elemental composition of the molten metal. 
External services as needed for the LPPSP system are provided through the control console. The console requires a supply of water at temperatures below $60^{\circ} \mathrm{F}$ at flowrates up to 10 gallons per minute in bursts of 20 to 30 seconds at a time. The electrical requirements are modest: two independent 115 VAC lines, each rated at $20 \mathrm{~A}$ with four three-conductor receptacles.

\section{Support console}

The support console provides a supply of inert gases and a vacuum pump for pneumatic control of the immersion process, on the one hand, and a supply of cryogenically cooled nitrogen for water-free cooling of the immersion tube, on the other.

\section{E. Software}

i) Data aquisition - The purpose of the LPPSP system is to aquire tractable spectroscopic emission intensities through LPP excitation of the representative molten metal surface. The entire hardware is devoted to facilitating this objective. The raw data are taken and stored locally at the LPPSP head within the first few microseconds of the firing of a high-power laser pulse. The next critical operation is to move the data to the two dedicated computers in the control console, and process and extract the elemental composition from the data. These operations are software intensive.

ii) Data analysis - The second function of the software is to sort the emission intensities by constituent elemental parentage, according to a spectral database. In view of the fact that the molten metal is invariably composed of ten to more than 25 
elements, that each element provides a wide assortment of emission lines, and that each emission line is spectrally broadened, the sorting is carried out as a pattern recognition process.

iii) Databases - Extensive databases provide support for the spectral analysis software. Three basic databases have been constructed: spectral; alloy composition; and calibration. The spectral database covers more than 25 elements, and contains for each element the basic data on atomic structure, emission line wavelength and intensity for all stages of ionization that are encountered within an LPP plume.

\section{F. LPPSP head manipulator}

Normally, the LPPSP head first approaches the molten metal bath at a pre-selected speed, and after a pre-determined distance of foray into the molten metal bath it reverses its travel to return to a pre-set disengaged position. By the end of the withdrawal operation, the computers in the control console have received the spectroscopic data from the LPPSP head and are well into the analysis. The time required for this immersion and withdrawal is about ten to fifteen seconds. Mechanically and electrically quiet execution of this immersion and withdrawal operation is instrumental to achieving the maximum precision of which the LPPSP system is capable. This consideration thus defines the criteria for the manipulator design.

Assuming that the slag layer is 12 inches deep, the basic dimensions of the second-generation LPPSP head are as follows: the main protective shell is 49 inches long and 14 inches in diameter; 
the immersion tube with the refractory sheath is 25 inches long and $7.250 "$ in diameter at the base where it joins to the shell and 4.750" at the leading end. The mounting bracket at the top of the LPPSP head, where the umbilical cord also connects to the head, adds another 13" to 25" to the total length, depending on the coupling scheme selected. The total weight of the LPPSP head including the umbilical cord and cooling water is estimated to be 600 pounds. The total length of the LPPSP head, which is fastened at the top to a manipulator for deplyment at a ladle metallurgy facility, is 87 inches. It has a maximum vertical travel of 47 inches, based on the assertion that the maximum depth of the slag layer is 12 inches. The control console is located about 30 feet away, preferably housed in a cubicle six feet wide, eight feet long and eight feet high.

The LPPSP head has been hardened to endure considerable mechanical impact, intermittent supernormal exposure to heat and uncontrolled electrical noises. To further insure robust performance, the LPPSP head manipulator must be operated with care in the following two areas: protection of the refractory sheath on the immersion tube, and electrical and mechanical noise management. Safeguards against electrical power failure, interruption of coolants or immersion beyond the length of the refractory sheath or the depth of the molten metal bath must be built into the the manipulator. The top surface of the slag layer is first detected by the LPPSP head, and the depth of the molten metal bath is derived from it. The minimum distance of immersion 
and the lowest safe position for the LPPSP head are established. Based on these pieces of data establishing the bounds of the manipulator movements, the manipulator must be able to execute:

i) wobble-free vertical motion of the LPPSP head at a constant speed, which is presettable;

ii) automatic reversal from descending motion to ascending motion at a preset minimum height;

iii) automatic return to a preset maximum height in the event of electrical power failure or interruption of coolant flows;

iv) lateral translation, preferrably by rotation about the axis of the manipulator support, on demand, permissible only when the LPPSP head is safely above the rim of the container of the molten metal;

v) initiation of a descending motion upon receiving a command from the control console;

vi) immediate reversal from a descending motion to an ascending motion upon receiving a command from the control console; and

vii) fast fluidization of any solidified crust of the slag layer, either by crushing or melting, so that an immersion of the LPPSP head into the molten metal below can be effected without damage to the refractory sheath of the immersion tube.

\section{G. Measurement sequence and time budget}

The overall sequence of the LPPSP system operation is summarized in Fig. 1. The time durations for the key individual segments of the operation are indicated. 


\section{H. Results output and communication}

The spectral data from each measurement run and the outputs resulting from the subsequent composition analysis for the molten metal are stored as a data file. The results of the analysis are also made available in the form of a hard copy, a display on the computer monitor, or a data file to be transmitted directly to a process control computer for the alloy manufacturing facility. It

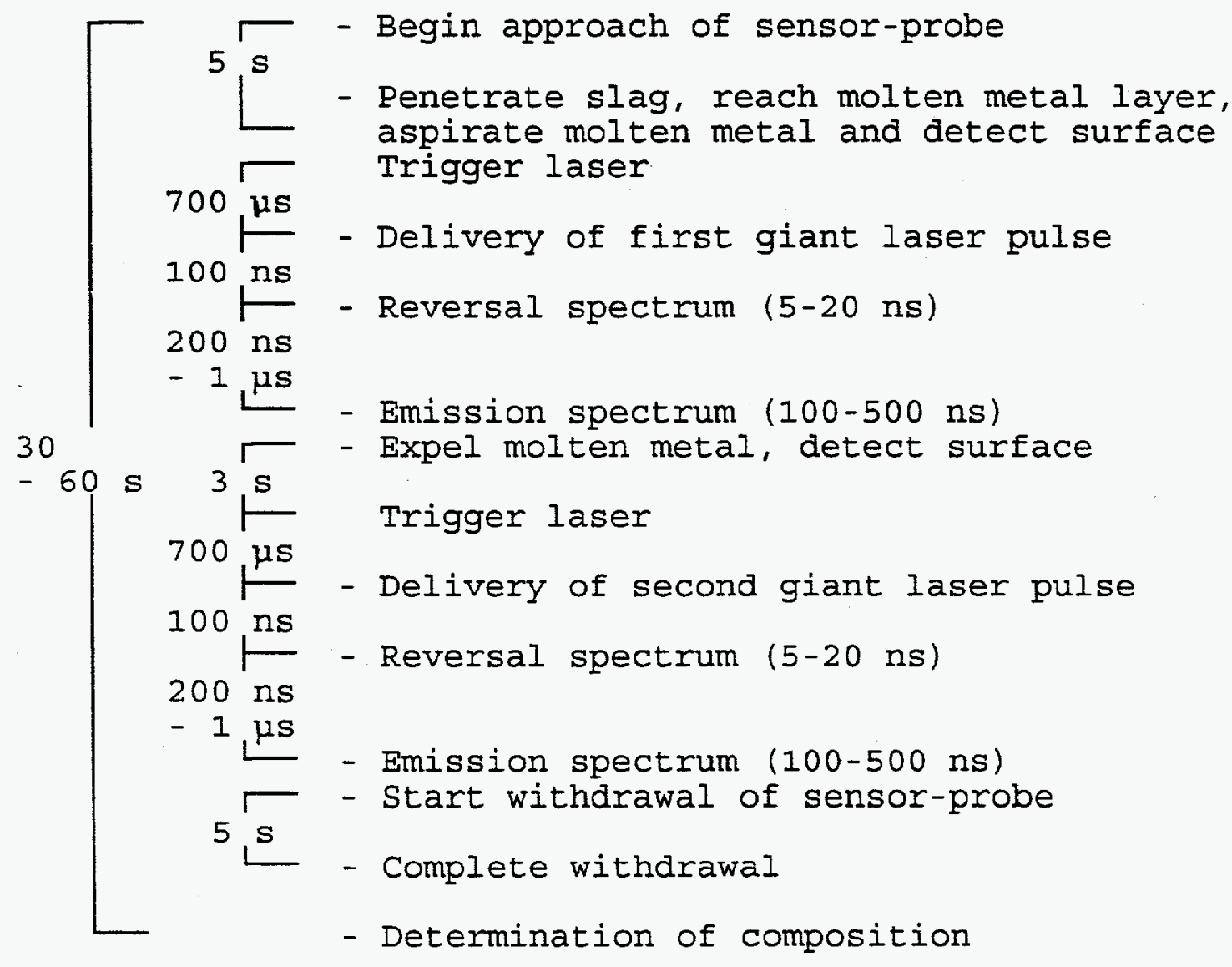

Fig. 1. LPPSP events diagram for double measurement mode.

is a simple matter of setting up the computers on the control console for the preferred form of the results output. The desired data format and transmission rate may be similarly selected. 


\section{Elemental composition analysis precision}

The ultimate precision possible for multi-element composition analysis by the LPP sensor-probe system is summarized in Table 2 for five key elements. Similar levels of precision can be

Table 2. Summary of the molten metal calibration data

Concentration

Element in $\mathrm{W} \%$

Carbon

$$
\begin{aligned}
& 0.01 \\
& 0.02 \\
& 0.10 \\
& 0.50 \\
& 1.0
\end{aligned}
$$

Manganese 0.3

1.0

1.4

Sulfur

$$
\begin{aligned}
& 0.05 \\
& 0.2 \\
& 0.4
\end{aligned}
$$

Silicon
0.05
0.3
0.5
1.0

$$
\begin{aligned}
& 0.01 \\
& 0.02 \\
& 0.05
\end{aligned}
$$

Percent Uncertainty

as Percentage of $\mathrm{W} \%$

1993 2nd Gen 3rd Gen

(1995)

+150
\pm 75
\pm 40
\pm 24
\pm 15

$\pm 40$

$\pm 20$

$\pm 10$

$\pm 6$

$\pm 4$

$\leq \pm 15$
$\leq \pm 8$
$\leq \pm 4$
$\leq \pm 3$
$\leq \pm 1.5$

$+13$

$\pm 5$

$\pm 6$

$\pm 4$

$\pm 1.5$

$\pm 1.5$

$\leq \pm 1.3$

$\leq \pm 0.5$

$\leq \pm 0.5$

$\pm 120$

$\pm 33$

$\pm 16$

$$
\begin{aligned}
& \pm 30 \\
& \pm 5 \\
& \pm 4
\end{aligned}
$$

$\leq \pm 12$

$\leq \pm 4$

$\leq \pm 1.5$

\pm 100
\pm 17
\pm 10
\pm 5

$\pm 25$

$\pm 5$

$\pm 3$

$\pm 1.5$

$\leq \pm 10$

$\leq \pm 1.5$

$\leq \pm 1$

$\leq \pm 0.5$

$\pm 50$

$\pm 25$

$\pm 10$

$\begin{array}{ll} \pm 13 & \leq \pm 5 \\ \pm 6 & \leq \pm 2.5 \\ \pm 2.5 & \leq \pm 1\end{array}$

realized for the other elements of interest; this expectation is based on the spectral response of the other elements to LPP excitations. It should be noted that the in-situ deployment of the LPP sensor-probe system can introduce additional uncertainties through many different routes. An exacting adherence to the design requirements of the entire LPPSP system as installed and 
operated can insure full realization of these precisions.

\section{J. Special features}

As a result of extensive interactions with more than a dozen steelmakers, foundries, and other metal alloy processors, the

LPPSP system has been enabled to provide numerous specialized functions and capabilities. These additional features of the third-generation LPPSP system, to be contrasted from the basic capabilities of the second-generation system, are summarized in the following.

i) Double measurements in each immersion into the molten metal bath;

ii) 25-plus element analysis per measurement run;

iii) Immersion into the molten metal bath at angles other than a vertical entry in order to accommodate many different configurations of melt shop furnaces;

iv) Thermal hardening of the protective shell and the immersion tube in order to handle those circumstances where thermal loads are exceptionally high or the residence time for the LPPSP head is extended;

v) Electrical hardening of the LPPSP system to the extent that the LPPSP head as well as the control console can be located in close proximity to the high electrical power sources such as an induction furnace and switching inductive loads, although each immersion into the molten metal bath would require a temporary suspension of the induction furnace for the duration;

vi) Mechanical hardening of the LPPSP head against mechnical 
vibrations and impacts imparted on the protective shell. This is accomplished largely by building the sensors and numerous interlocking optical components on a platform that is independent of the protective shell. Internal sensors and actuators are also employed for tracking of the alignments and corrective adjustments ;

vii) Self-calibration maintenance by a combination of long-term tracking of the aging process (i.e., wear and fouling) of various optical components and corrective adjustments by means of imbedded actuators;

viii) Self-repair capability rendered by redundancy, performance tracking, shifting of functional loads from one component to another, and corrective adjustements by imbedded actuators;

ix) Slag or flue gas analysis, in addition to, or instead of, the molten metal analysis by shifting the designated targets for production of an LPP plume from the molten metal surface to a slag surface or a gas volume. The respective elemental composition can be deteremined in a comparable time frame. The switching of the analysis target is accomplished by change of the programmed LPPSP system operation;

x) Rapid turn-around, making it possible to carry out measurement runs as fast as once per minute. This has been accomplished by reducing the maintenance requirements for the immersion tube to an absolute minimum and high-speed initialization of the laser and detectors; 
xi) Low maintenance refractory sheath by selection of high-performance materials and an advanced method for putting together the multiple-component sheath assembly;

xii) AOD vessel option, as facilitated by combining oblique-entry immersion, an extended-length immersion tube, and use of a thermal radiation shield over the protective shell and umbilical cord;

xiii) BOF option, as facilitated by installing a water-cooled cylindrical guide within which the LPPSP head and the umbilical cord are confined to move;

xiv) Miniaturization of the LPPSP system to $5^{\prime \prime}$ diameter or smaller is possible for exceptional applications where space is at a premium. For the standard configurations of the LPPSP system as described above, if the number of elements for analysis is reduced to about 12 instead of the full 25-plus element menu, the size of the LPPSP head can be reduced to less than 10" in diameter;

xv) Reduced package options possible for specialized

applications. Examples include a continuous tracking of a few key elements in a molten metal bath as a process indicator, where drastic reductions in the size and complexity of the entire LPPSP system can be realized.

III. SUMMARY OF SCIENTIFIC MILESTONE TASKS

The scientific issues inherent in the above four stages are grouped into the milestone tasks for the Phase B investigation, and they are described in the following. 
1. Implementation of molten metal calibration protocol

A new calibration protocol for molten metal analysis is needed for two different reasons: First, the interaction of a laser pulse with a molten metal is distinctly different from that of the same alloy in solid phase due to the fact the process of melting is absent and the transport properties and optical reflectance differ a great deal between the two phases. Second, the conventional dependence on certified standards for solid specimen analysis breaks down because, upon melting, the elemental composition of a standard specimen undergoes rapid and significant changes with time.

For solid specimen analysis, the calibration procedure had evolved over several decades through the process of multiple measurements by independent laboratories, the key ingredient being the use of certified "like" standards. We have thus developed a new protocol for molten metal analysis which allows contact with this framework for solid specimen analysis.

It begins with a crucible-free molten metal source that can be rapidly quenched immediately after an LPP analysis. The resolidified specimen is analyzed by conventional means, and the results fix the concentrations of various elements in the molten metal specimen immediately before solidification, thus providing the molten specimen standard. This allows a reconnection to the solid specimen analysis protocol. The molten metal specimen is produced by melting one end of a 2 "-long rod specimen of $1 / 4$ " diameter inside a RF levitation-assisted molten metal source, 
which is described next.

i) Levitation-assisted molten steel source

The levitator-heater for producing molten metal specimens is powered by an $15 \mathrm{~kW}$ RF power generator, operating at frequencies from 70 to $200 \mathrm{kHz}$. The RF coil has the basic levitator-heater design with three turns and a fourth turn in reverse at the top. The diameter of the levitator-heater coil is about $3.0 \mathrm{~cm}$ at its maximum. A metallic rod specimen of 1/4" diameter and 2" length is placed vertically just below the minimum-B point. The top end is heated to melting while being supported by the levitation field; this prevents the molten metal from spilling over. When the RF power is turned off, the molten metal at the tip is rapidly quenched into solid, in less than one half of a second. The specimen rod is removed. The $0.050 "$ tip of of the domed resolidified end is ground off to expose a flat surface, and both ends are analyzed for composition by the conventional methods. This provides a quantitative measure of the changes an alloy specimen undergoes during a rapid melting. In addition, the composition of the molten metal is firmly established.

In view of the fact that the composition undergoes a measurable change during the period of three to five seconds when one end of the specimen rod is in a molten state, it becomes very important to keep the time of heating and melting reproducible from one specimen to the next. The variability in these times arise from the uncertainties in the dimensions and the placement of the specimen within the levitator-heater coil, variability in 
the tightness of the clamping of the specimen in the specimen holder, power fluctuations of the RF generator, and the variations in the elemental composition of the specimen. Strict control of the physical aspects of heating and melting has been enforced. Individual specimens have been cut out of a same stock rod of an alloy so that changes in the composition may be minimized.

The alloy composition must be deliberately changed in order to attain at least three different concentrations for each element of interest. This leads to a wide variations in the electrical resistivity, thermal conductivity, and phase transform properties of the alloy specimen. All of these play significant roles in the heating and melting times. The goal is to keep these times reasonably close to each other so that the composition change due to melting can be minimized. In order to help guide the selection of the RF power level with a new alloy specimen, a detailed numerical simulation of the heating and melting has been carried out for a wide range of specimen materials and dimensions.

Tables of thermophysical properties as a function of temperature were assembled from published data for numerous steel alloys. Missing data points were filled in by interpolation and by comparison with the thermal behaviors of other similar materials in some cases. Using the specimen and specimen holder as heat sinks, the coupling of the RF input power in a small time increment is calculated and the absorbed energy is partitioned into conduction, internal energy, radiative cooling, and latent heats of phase changes. The RF power levels were sought for each 
alloy such that overall time to melting is between 20 to 40 seconds, with the time duration of molten state being three to five seconds.

The major findings of the numerical simulation are summarized in Fig. 2. The results are organized as scale factors to be

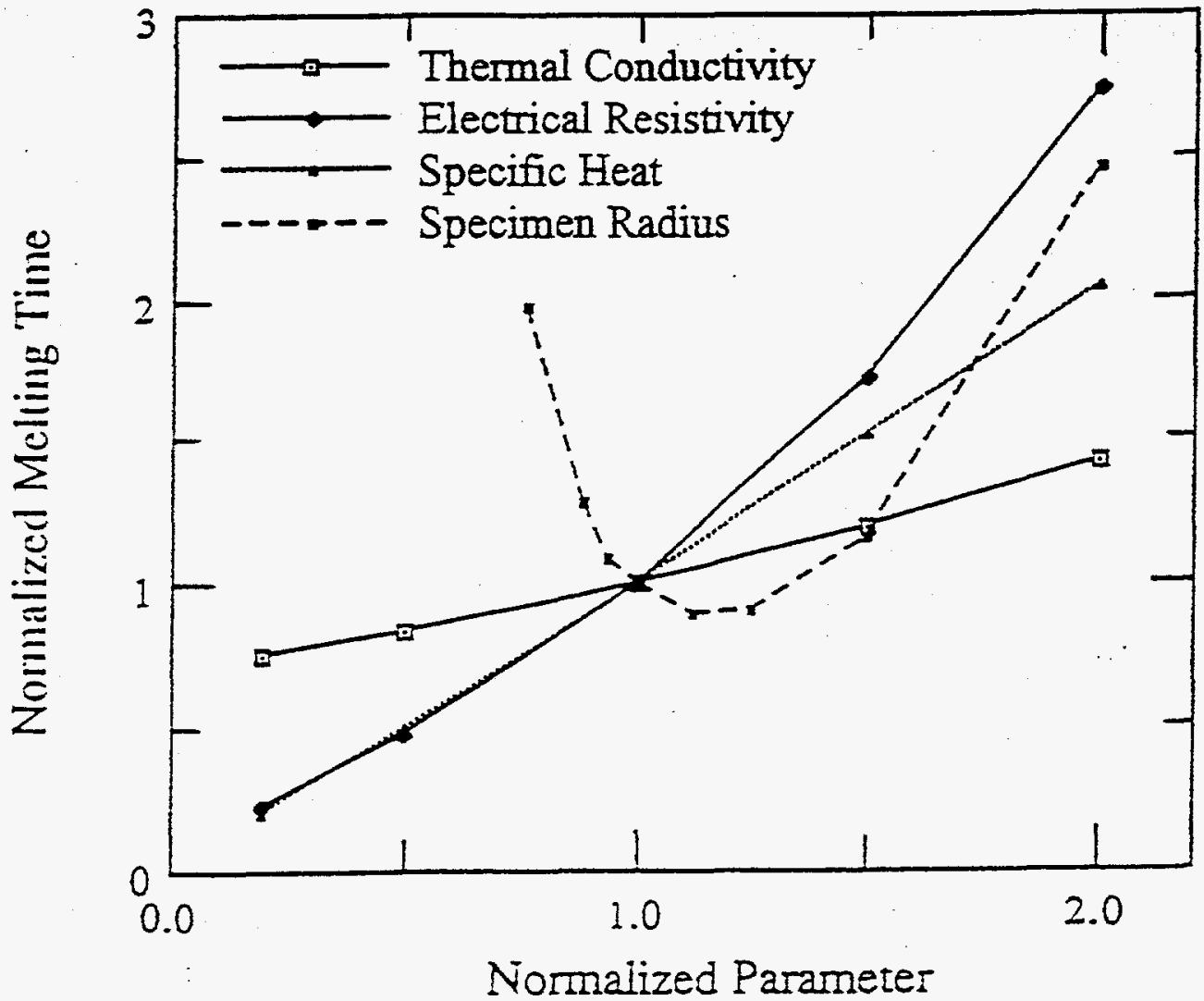

Fig. 2. The normalized time of heating to the onset of melting as a function of normalized values for specimen diameter, electrical resisitivity, thermal conductivity and specific heat. The reference point of normalization is indicated where both the ordinate and abscissa read unity and the specimen diameter is 1/4". Only one physical parameter is changed at a time to calculate the factor by which the time of heating is changed, as shown. The RF heater power is kept at a constant level for all calculations. 
multiplied to the heating time to the onset of melting of a reference material. Only one of the four properties has been changed at a time.

There are other factors affecting the reproducibility of the LPP plume as far as its elemetal emission spectra concerned. The way the laser pulse interacts with the molten metal surface can be affected widely depending on the thin layers of impurities that float irregularly on the molten metal surface. The procedure to minimize this kind of variability is to let the eddy current due to the RF heating clear the impurity layer, and such determination can be made by inspection of the molten metal surface. In order to further improve this selection process while maintaining the time of melting in a narrow range, we have developed a transducer that is sensitive to this surface impurity layer. It measures the impulse imparted on the molten metal target by the LPP plume ablation. This impulse transducer is described next.

ii) Impulse transducer for LPP plume selection

The key requirement for any useful application of the laser-produced plume resulting from pulsed laser heating of the condensed-phase target is that the plasma be of the same elemental composition as the target. In a fundamental way, this requirement provides the basis for highly reproducible plasma production and thus facilitates quantitative measurement and calibration. our investigation has established that the necessary and sufficient condition for satisfying the requirement is to keep the velocity of the target surface movement due to laser ablation approximately 
the same as that of the thermal diffusion front propagating into the bulk. It follows that for such a representative plasma there exists an explicit relationship between the thermal diffusivity and the amount of the target material ablated during a single laser exposure. For a laser pulse of given energy, the thermodynamic property of an LPP plume varies according to the thermophysical properties of the target surface layer including the thermal diffusivity, and such properties are affected by the elemental composition. The amount of the surface matter that is ablated by the laser pulse is then an excellent indicator of the likeness of LPP plumes.

The total mass of the laser ablated target material can be quantified for each laser pulse through measurement of the impulse imparted on the target by the ablated mass in the process. The rate of mass removal scales with the thermal diffusivity of the target matter, subject to the energy cost of evaporation and the plasma plume's ability to disperse away from the target surface so that the evaporation process can continue. This means that the thickness of surface ablation grows inversely with the heat of formation and decreases with increasing molecular weight. This has resulted in a significant new technique for determination of the thermal diffusivity and other related thermophysical properties of materials in a liquid or solid phase at high temperatures, hitherto unaccessable by conventional methods.

In the present context of calibrating the LPP analysis for molten metal composition determination, the precision of the LPP 
composition analysis method can be rigorously established by sorting the LPP plumes by the impulse imparted on the specimen holder. For this purpose, a new impulse transducer has been developed. The transducer consists of a force gauge incorporated into the base of the specimen holder of the RF levitator-heater. Fig. 3 shows schematically the impulse transducer. The entire upper part of the specimen holder is spring-loaded onto a piezoelectric force gauge (Kistler model 9702). The impulse from the LPP plume drives the upper part of the specimen holder, including the specimen, into motion, and this displacement is detected by the piezoelectric force gauge after a characteristic time delay.

The transducer is then calibrated, as assembled, by dropping a steel bearing ball from a known distance above. The time of flight over a fixed distance interval is measured before, and after, each impact so that the coefficient of restitution can be determined and the impulse calculated. The distance of fall and the size of the ball are varied in order to change the impulse. Maintaining a constant pressure contact with the force gauge is crucial to the accuracy and reproducibility. This is effected by using a coarse spring. The spring is anchored at the bottom of the upper part of the specimen holder and is screwed into a female thread machined into the lower part; before each run the spring tension is reinitialized by twisting the upper part of the specimen holder against the lower part. A calibration curve is 


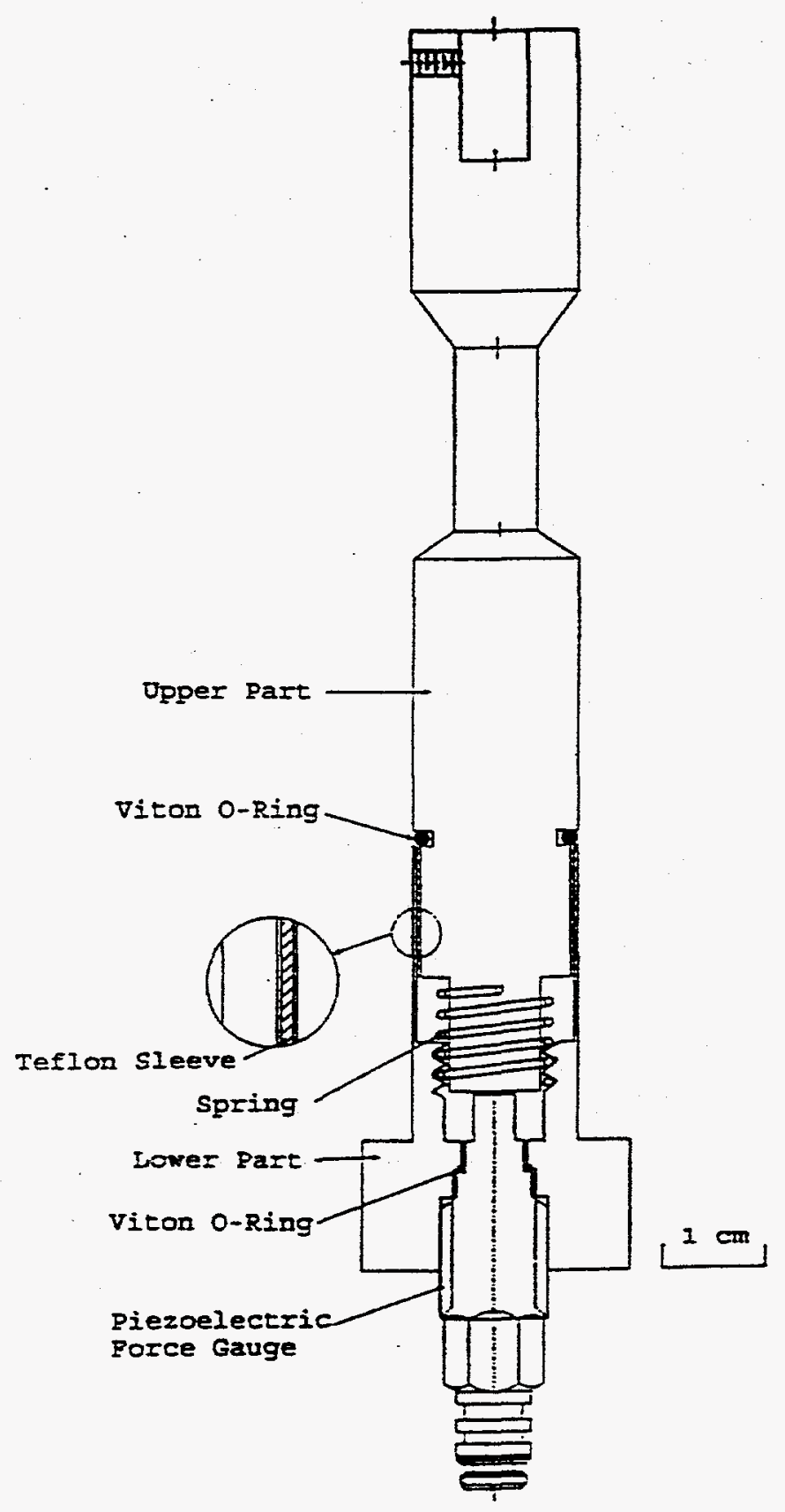

Fig. 3. Schematic diagram of the impulse transducer, as mounted at the base of the specimen holder. Normally, a specimen of 1/4" diameter and $2 "$ length is mounted at the top. The specimen holder is inserted into the RF levitator/heater through a vacuum feedthrough, placing the top of the specimen within the RF levitor/heater coil, just below the point of the magnetic field minimum. 
generated for each alloy specimen by measuring the maximum value of the transducer output.

The overall performance of the impulse transducer is summarized in the next three figures. The calibration of the transducer is shown in Fig. 4, as obtained from the measurements of falling spheres. This demonstrates the linearity of the transducer. Notice, however, that since the impulse generated by

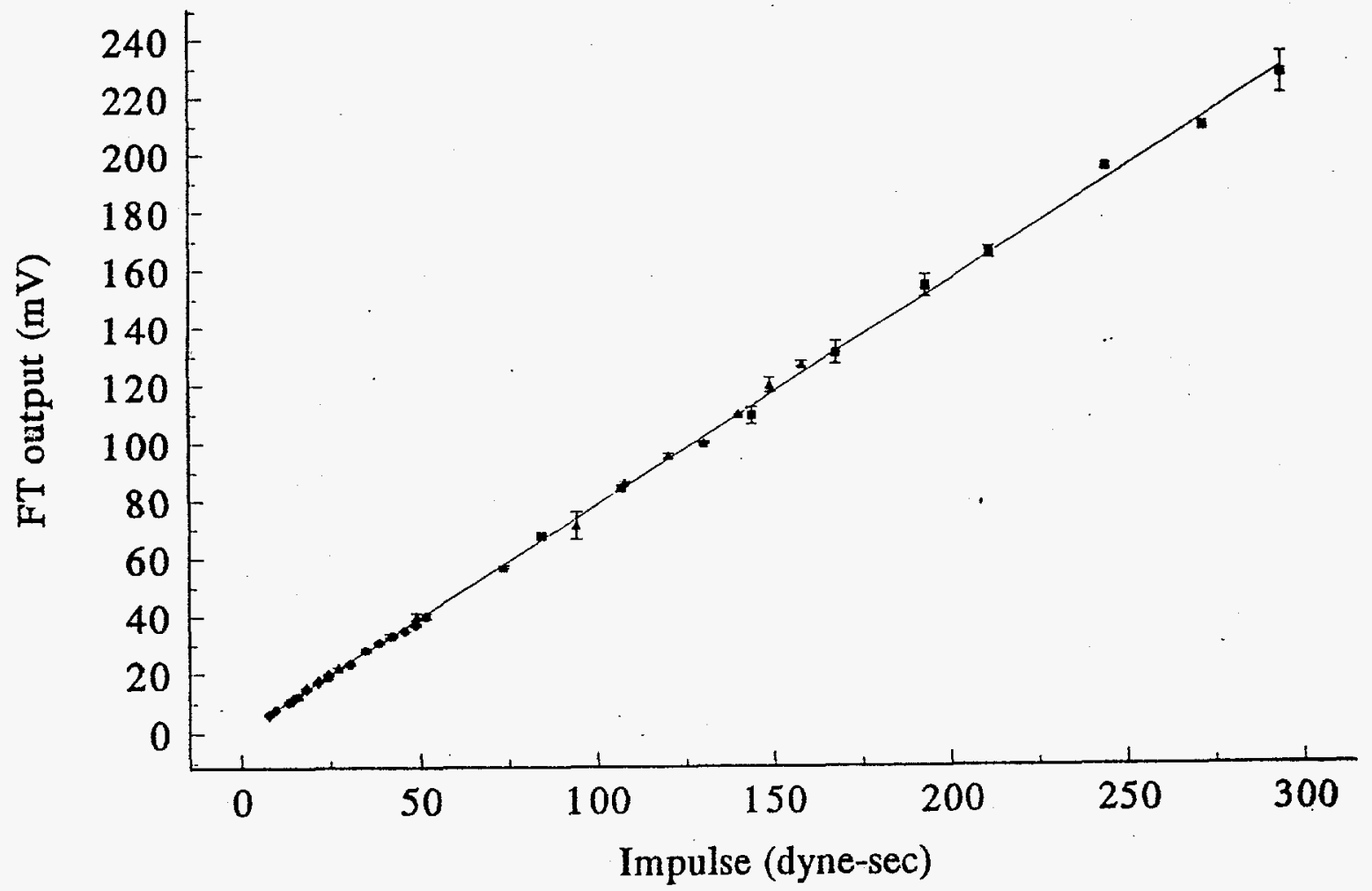

Fig. 4. Calibration of the impulse transducer against the measured impact of a falling steel sphere. 
an LPP plume evolves over a nanosecond to microsecond time regime, the impulse registered in the transducer, which responds to sub-millisecond time regime, represents a response proportional to a time integral of the impulse. The calibration runs are for the instantaneous impulses due to impact by the falling steel balls. A sequence of five successive LPP runs on a solid copper is shown in Fig. 5. First, notice the remarkable regularity with which the

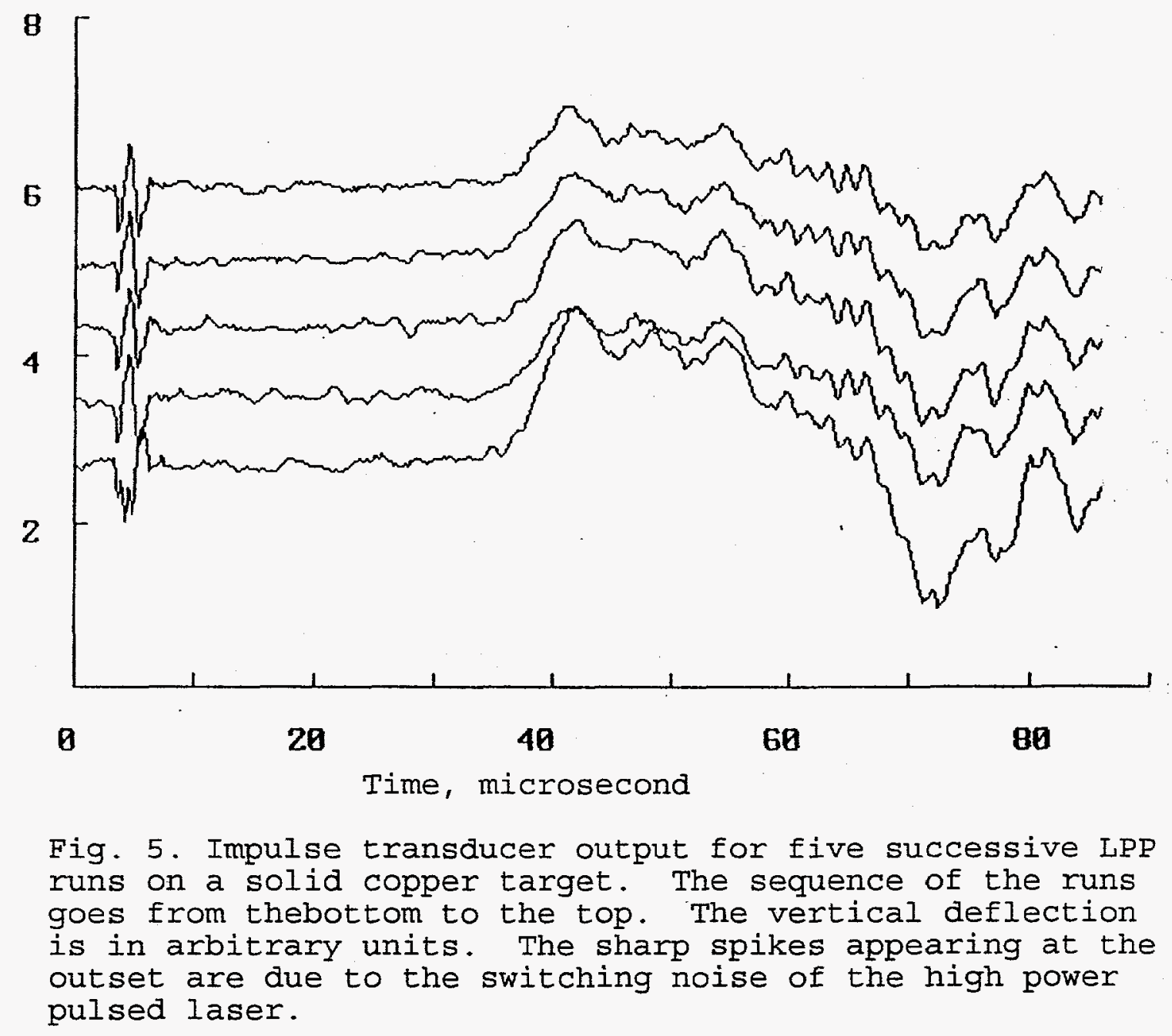


response is detected. Secondly, it is sensitive enough to discriminate the succeeding LPP runs as the layers of the surface is removed; this is consistent with the spectrocopic observation of the LPP plumes in that the solid specimen surface is covered with oxides and other contaminants and requires several LPP exposures to reach the bulk layer of the alloy.

Fig. 6 shows the impulse measurements made on four separate molten SS316 specimens within the levitator-heater. Due to the

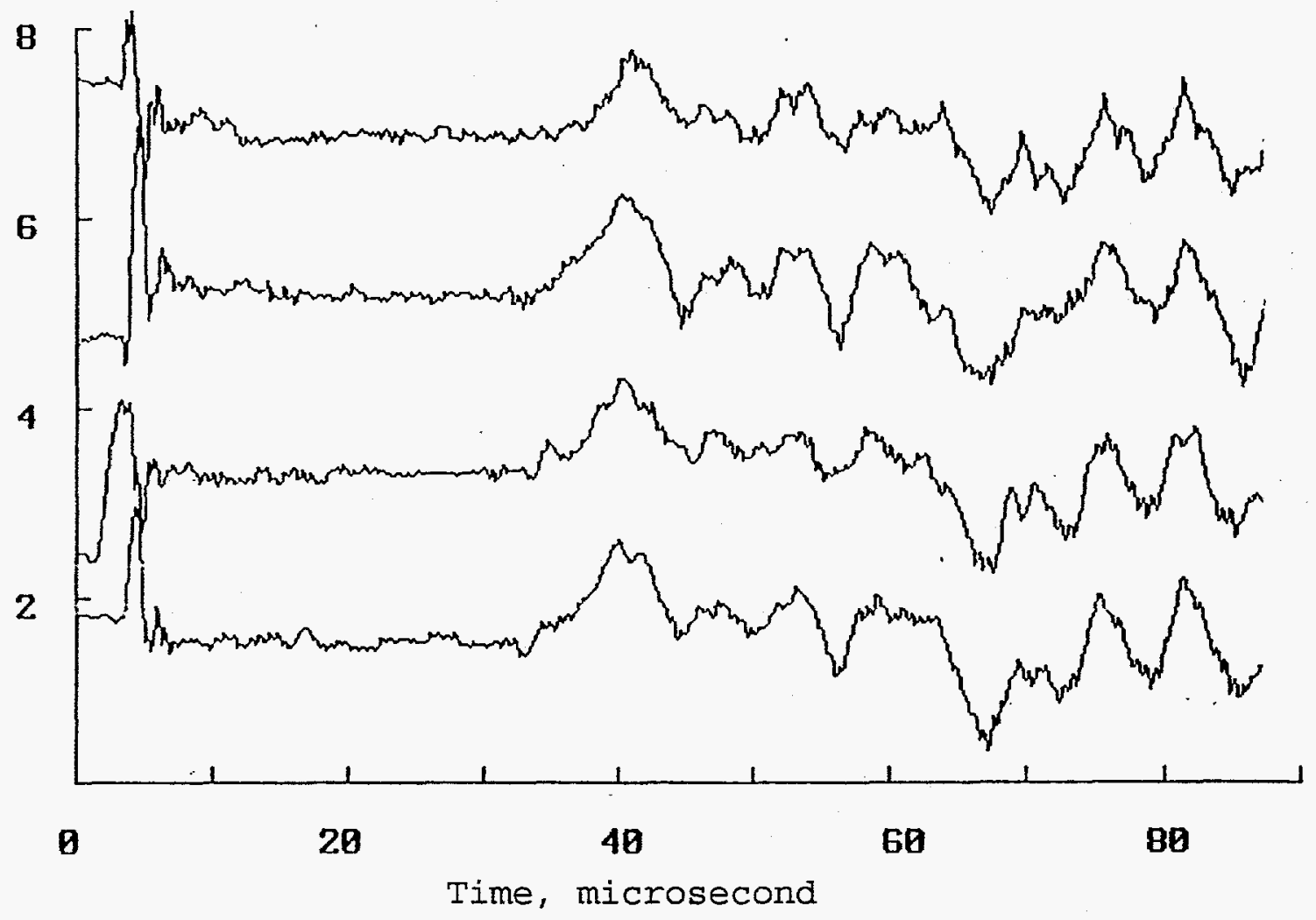

Fig. 6. Impulse signals for four molten SS316 specimens. The vertical deflection is given in arbitray units. The sharp spikes appearing at the outset are due to the switching noise of the high power pulsed laser. Four different specimens were brought to melting individually starting from room temperature. A signal processing was applied to the transducer output to remove a large periodic RF heater noise. 
variability in the heating time, alignment of the dome of the molten metal specimen with the optics of the laser beam and spectroscopic detectors, the impulse varies. The main point here is that the impulse measurement makes it possible to exclude those runs with measured impulses falling outside of a predetermined optimal range from the database of the molten metal calibration. We have thus far accomplished $\pm 2 \%$ uncertanity in maximum impulse measurement for solid specimens and $\pm 4 \%$ for molten metal specimens. By means of the calibration curves, the result can be converted into the impulse at the surface due to LPP ablation for determination of the thermal diffusivity of the molten metal. More importantly, this process of selection provides the ultimate precision achievable for the composition analysis by laser-produced plasmas.

Detailed calibration studies were carried out for five elements, C, Si, Mn, Al and S, by means of the new molten metal calibration protocol as implemented in the levitation-assisted molten metal source. The results are summarized in Table 2 .

To further extend the list of elements, three different alloys containing twelve additional elements, each covering the concentration range appropriate for the range of alloys produced in the industry have been prepared. These alloys were individually machined into rod-shaped specimens. The additional elements are: $\mathrm{Cr}, \mathrm{Ni}, \mathrm{Mo}, \mathrm{Cu}, \mathrm{Co}, \mathrm{V}, \mathrm{Ti}, \mathrm{Cb}, \mathrm{P}, \mathrm{Sn}, \mathrm{W}$, and $\mathrm{B}$. Many elements can be brought into the calibration database in a similar manner. 


\section{2 . Considerations of the analysis precision}

Calibration of the quantitative spectral data as obtained from LPP analyses of molten metal specimens, according to the protocol, involves a sequence of several discrete steps. These steps have been examined systematically for respective contributions to the overall measurement noise. There are two types of noise sources: intrinsic and extrinsic. The intrinsic sources are the detector-related noises, on the one hand, and the finite nature of photon counts at each spectral emission, on the other. The detector-related noises consist of the thermal noise within the spectroscopic detectors and the read-out noise associated with extracting the stored analog intensity values from individual detector elements and digitizing them prior to transfering them to the computers. The extrinsic noises arise from: variability in the logistics of RF levitation-assisted melting; variability in elemental composition of alloy specimens; misalignment of specimens with LPP optics and timing jitters with LPP plume spectroscopy; and environmental noises, both mechanical and electrical, contributing to the measurement process.

The remedies include: 16-fold increase in light-gathering optics; cooling of detectors to reduce thermal noise; increased detected signal dynamic range by separate grouping of low versus high intensity lines and by significant increase of maximum digital resolution; and tighter control of the molten metal calibration process. The control here is multiple fronted, including: stringent selection of reference alloy specimens; close 
monitoring of the timing of molten state for LPP excitation; uniform, shortened heating and melting time; and LPP plume selection by means of the impulse transducer.

The results of these advances on the measurement precision are summarized in three different columns of Table 2. Going from the left to the right, these columns present the results for the first set of molten metal calibration runs by simulated LPP sensor-probe measurements, for the second-generation system and for the third-generation LPPSP system, respectively.

3. Performance of immersion tube sheath in molten steel The immersion tube of the sensor-probe head is protected by a refractory sheathm, which is thermal shock resistant and remains free from a build-up of solidified slag and metal after each immersion into a molten metal bath. The full sheath assembly has large dimensions in comparison with the dimensions of available stocks of the raw materials, and is consequently composed of interlocking machined parts. The long term performance of the refractory sheath has been evaluated by immersing simulated scale-model assemblies into a variety of laboratory molten steel sources. The results show highly satisfactory performance throughout repeated immersions. The basic requirements that the sheath remain non-wetting, free of cummulative surface erosions, and chemically inert in the molten steel bath have all been met.

The overall long-term performance of the fully scaled-up sheath assembly has been the remaining issue, as one of the objectives of the field deployment of the LPPSP system. This was 
addressed in a series of full-scale immersion runs at a foundry during the period 1995-96. The LPPSP head was cooled under the dual-zone cooling scheme: cooling of the protective shell by municipal water, and cooling of the immersion tube with cryogenic gas. The gas boiling off from a cryogenic liquid reservoir was forced to flow through the coolant channels within the stainless steel support structure encased under the refractory sheath. The sheath assembly performed well during the immersion and withdrawal sequence. The overall assembly was allowed to rise in temperature to that of the molten iron bath, and the molten metal was aspirated into, and then expelled out of, the tube under pneumatic control. As the immersion tube was withdrawn from the molten iron bath, both the slag and molten iron dripped off cleanly from the sheath surface without incurring any surface damages. The surface of the sheath assembly glowed in red and rapidly cooled off in the next ten to twenty seconds. Then, there emerged slowly a hairline fracture at the very end of the immersion tube. This phenomenon was eventually traced to the fact that delayed heating and associated expansion of the stainless steel support structure underneath the refractory sheath. The cryogenic gas cooling was unable to dispose of the large flux of heat conducted through the sheath over time. This was the direct consequence of having to forego with water-cooling at the melt shop operators' insistence. Another finding is that the molten iron as well as the molten steel has proven to be so fluid that it readily seeps into the gaps between adjoining parts of the 
assembly. This could present a potential problem by thermal expansion at later re-immersions.

The main solution to the above problem has been to be more aggressive with the cooling by cryogenic gases. An alternative, technically much simpler solution has been the original water cooling scheme. It is still posssible that, as the field deployment experience accummulates, the industry may become more receptive to this approach.

\section{Hardware integration}

The LPPSP system combines extremely diverse components of optics, power sources, spectroscopy, electro-optics, mechanical structures and actuators, thermal shields, fluid flows, analog and digital electronics, controllers, and computers. In addition, the specific noise reducing remedies, both electrical and mechanical, have been built into the hardware. The combination of a new large area optics and 2-D array detectors together increases the signalto-noise ratio by orders of magnitude. Integration is the paradigm in this system. The essential support and protection is all organized through one control console. The basic consumable supplies are channeled to the control console from the support console.

Self-maintenance of the calibration and other alignment of the optics, electronics, and pneumatic controllers and sensors is integrated in that each measurement run provides the basic data on the deviations from the fiducial references. Self-repair decisions concerning the hardware are similarly organized. 
In detail, a very large number of modifications have been made to the basic hierarchy of the hardware because of many new requirements forced on the system by the operators of the potential host site facilities. Such modifications are specifically treated in later sections.

In order to facilitate implementation of the modifications and the flow of deployment-related activities, the LPPSP system is organized into two generations. The first wave of field deployment is done with the second-generation LPPSP system, which lacks certain capabilities such as dual measurement, self-repair and 25-plus element analysis, but in all other respects is fully equivalent to the final, third-generation system. The third-generation LPPSP system has the full embellishment of the specifications described in Section II. The second-generation system is then upgraded to the third-generation specifications at the conclusion of the inital trial period of the field deployment. Wherever appropriate, this system can remain in service indefinitely.

\section{Software integration}

The entire sensor-probe system is operated under software control. The software modules are organized by functions into three broad areas: data acquisition; data analysis; and spectral and calibration databases, as itemized in section II.2.E. Individual modules specialize: immersion operation including rangefinding, pneumatic control, and LPP plume timing; spectral data collection; data transmission to the computer; signal 
processing for spectrally-resolved intensity determination; interpretation of measured intensity by means of the calibration database linking the spectral intensities to elemental concentrations; monitoring of drifts in instrument alignment and sensitivity; and other housekeeping activities. The speed of execution is of a primary consideration in the context of real-time analysis, impacting on the manner of the integration of different software modules. The numerous new requirements for the LPPSP system, as mentioned above and further elaborated later, have forced significant revisions on the software integration. As the shop-, and process-, specific deployment issues are addressed individually, further fine tuning of the software modules will continue.

\section{Adaptation to shop-specific environment}

Altogether, eight steelmaking facilities, four in specialty steel and four in low alloy steel, have been engaged in in-depth discussions as potential host sites for deployment of the LPPSP system. It has been found that each individual metal production shop is by and large unique in the mode of operation and in the physical layout. Even within a shop, the molten metal bath is handled differently according to the main process at that location. A shop-specific and process-specific site preparation is thus expected. Generally, the sensor-probe head must be inserted and withdrawn from a molten metal bath on demand. A remotely controlled manipulator is needed for this purpose at a location that is optimal from the standpoint of minimizing 
disruptions to the pyrometallurgical processes and raw material flows in the shop and also of maximizing safety to the system hardware and research personnel. In addition, the extent of the protection that the LPPSP head and umbilical cord need against thermal exposure vary widely. Three basic configurations for the manipulator have been developed. The final design, fabrication and installation of the manipulator, however, require close collaboration with the operators of the host site facilities because a robust deployment requires an integration of the LPPSP system into the steelmaking facilities.

The three basic configurations are as follows: i) For ladles containing a batch of molten metal, the minimum requirements for the manipulator are sufficient, which have been stated in section II.2.F; ii) For an AOD vessel, the entry of the LPPSP head into the vessel, its immersion into the molten metal bath, and the subsequent withdrawal from the bath and the vessel all have to be coordinated by a single manipulator. Given that the entry is possible only when the AOD vessel is tilted into a near horizontal position, the manipulator must also be capable of rotating the LPPSP head by more than $45^{\circ}$ out of the vertical axis. An additional thermal shield is needed covering the protective shell and a part of the umbilical cord, as described in section II.2.J; and iii) For deployment in a BOF or other melt shop furnaces, an actively cooled cylindrical tube is needed within which the LPPSP head can be translated axially in order to effect the immersion operation. This tube may be a permanent installation built into 
the roof or side wall of the furnace. Alternatively, a manipulator first projects the tube into the furnace through a hatch on the roof of the furnace, and then drives the LPPSP head further into the molten metal bath for the immersion operation. The specific design concepts have been fully worked out for these scenarios.

\section{Self-repair and adjustment capabilities}

The LPP sensor-probe system is a complex high-density instrumentation package, and as such, is best provided with capabilities for self-repair and adjustment, given that its sphere of applications will be in a production shop rather than at a service facility. This design objective is met by endowing the system with: a high degree of programmability; redundancy; a set of strategically placed sensor transducers and actuators; and capabilities for acquiring arbitrarily massive amounts of spectral data. The software will then help make appropriate choices whenever intervention is needed. A significant portion of these capabilities have already been implemented in the second-generation system; full implementation is effected in the third-generation LPPSP system.

\section{Mechanical, thermal and electrical hardening}

The second-generation LPPSP system designated for the field deployment has been ruggedized to the point of being shop-worthy. The mechanical and electrical hardening has been verified in a series of laboratory tests under a variety of simulated threat conditions and through the trial runs conducted at a foundry, 
where full-scale hazards exist under normal production conditions.

IV. ISSUES ASSOCIATED WITH FIELD DEPLOYMENT OF LPPSP SYSTEM

The overall project has had a number of major technical parameter changes, causing substantial detours from the carefully constructed milestone schedule. These changes were forced on the project in the course of intensive dialogs with the operators of the steelmaking facilities as potential host sites for field deployment of the LPPSP systems and in the process of implementing the logistical issues of the technology transfer process. The new requirements may be grouped into the following nine categories.

\section{New requirements}

i) The first new requirement is that the sensor-probe system be applied to an AOD vessel, rather than to a molten metal ladle, which had been the target facility. Deployments in AOD vessels escalate the harshness of the operating environment in that the thermal exposure would be much greater because not only the leading end of the immersion tube but also the entire protective shell and a significant portion of the umbilical cord would be exposed to thermal loading comparable to the molten metal proper. The AOD vessel forms a blackbody cavity at the molten metal temperature. A dual-zone cooling provision had to be incorporated into an otherwise nearly completed LPPSP head, forcing substantial design changes.

ii) The second new requirement is that one of the potential host site raised an objection to water cooling of the immersion 
tube of the LPPSP head. This requirement necessitated the provision for cryogenic gas cooling of the immersion tube.

iii) Thirdly, the AOD vessel environment requires that the angle of penetration into the molten metal bath be substantially different from the normal incidence, $i . e .$, at angles as large as 45 degrees from the normal. This significantly impacts the kinetics of the formation of the laser-produced plasmas and all of the attendant calibration and signal-to-noise ratio issues.

iv) The fourth new requirement came up due to the discovery that the individual shop operators did not have a reliable method for determining the position of the molten steel surface. This prompted the development and introduction of a reliable method for such a determination into the LPP sensor-probe system.

v) The fifth new requirement is that the umbilical cord between the sensor-probe head and the control console be lengthened to about 50 feet from the 25 foot length that had been in the original design. This was driven by the required deployment into the AOD vessel environment, on the one hand, and due to a particular foundry layout where the first immersion tests were conducted, on the other.

vi) The sixth new requirement is that a new temperature measurement capability, which is integrated into the LPPSP system, is strongly desired by the shop operators.

vii) The seventh new rquirement is a capability to make two measurements during a single immersion. The steel plant operators have expressed a strong desire to have two back-to-back 
composition analyses made by the LPP sensor-probe system so that an average can be made of the two results. This is rather counter to the driving rationale for achieving real-time process control by means of the LPP sensor-probe system. The LPPSP system has been rigorously evaluated for its intrinsic single-shot reproducibility. In view of the fact that this concern is a result of the cultural and human engineering inertia, the decision to include an option for double measurements in a single immersion had to be made.

viii) The eighth new requirement is the capability for 25-plus element analysis. When the project was first initiated, the CTU 5-2 Consortium and other interested parties from the metals industry anticipated that the elements of interest would number at most ten to fifteen. The wish list has since grown to more than twenty five, and there is no firm figure at the present time as to what the maximum number will be. It is not clear whether this open-endedness is a reflection on increasingly complex alloying anticipated by the industry, or it is an indication of the growing ambiguities of the technical direction taken by the metals industry. It could also be that the metals industry is so emboldened by the capabilities of the LPPSP system that they wish to analyze for every conceivable alloying elements. We have nevertheless made provisions to accommodate the growing list of elements for simultaneous analysis. So far, we have found no chemical elements normally used in metal alloys that could not be detected to a sufficient resolution for quantitative analysis. 
Full 25-plus element analysis capability has been incorporated into the third-generation LPPSP system.

ix) The ninth new requiremeent is to convert all

special-purpose analog electronic circuits to general-purpose digital electronics. This is an outcome of preparing for the transfer of the technical design and construction specifications of the LPPSP system to the designated manufacturer as part of the technology transfer process.

2. Technical Parameter Changes due to the New Reguirements These new requirements had to accepted because of the basic nature of the necessary deployment process, but they have incurred massive new undertakings. Several major new features have been developed and incorporated into the two generations of the LPP sensor-probe system. Each new feature or capability added has resulted in technical parameter changes, affecting the design and functions of several major sections of the LPPSP system. The consequences have been individually evaluated and dealt with. The following are the outcomes of these efforts:

i) Capability for deploying LPPSP systems into AOD vessels;

ii) Capability for dual-zone cooling provision;

iii) Capability for detection of the top of the slag layer;

iv) Capability for in-situ molten metal temperature measurement;

v) Capability for double measurements per immersion; and vi) Revised system integration. 
V. TECHNOLOY TRANSFER ISSUES

Technology transfer has been in the overall milestone plan from the start of the project. The University has completed the process of selecting a manufacturer for the LPPSP system for marketing in the territory of the North American continent. A licensing agreement has been signed between the University and Bailey Engineers, Inc., as the designated manufacturer of the system for steelmaking applications for this territory. The process of licensing will continue for other territories and in areas of applications of the technology other than steelmaking.

Implementation of the transfer of the technology to the designated manufacturer requies a series of preparations as follows: i) development of full documentation, covering software, component fabrication procedures, assembly procedures, maintenance procedures, and alignment and operation procedures; and ii) continuation of various patent protection and maintenance processes.

VI. CONCLUSIONS

The scientific and technical progress with the Phase III-A and -B segment of the LPPSP project has been an unqualified success. A truly path-breaking technology has been perfected and its full implemetation into a shop-worthy LPPSP system has been accomplished. The system has been taken through the rigors of performance and survival requirements individually by the mechanism of intensive interactions with the operators of eight 
major steelmaking shops while identifying the potential host site facilities. The system has also been scrutinized from the technology transfer standpoint for the LPPSP system as a commercially manufactured instrumentation. The third-generation system incorporates all of the originally envisioned capabilities as well as those desired by the steelmakers as a truly robust process control tool. The second-generation LPPSP system has been constructed for the purpose of initial deployment in full-scale steelmaking shops. The third-generation system is nearing completion. Each of these systems will be individually exercised using a new large volume molten steel source, in addition to the full-scale deployment. The laboratory source, more than $1 \mathrm{ft}^{3}$ in molten metal volume, is coming on-line just now within the research laboratory of the Physics Department at Lehigh University.

The long-term performance of the LPPSP system will need to be closely monitored under the field deployment conditions. In particular, the issues to be focussed on are: the overall wear characteristics of the refractory sheath assembly of the immersion tube; the long-term performance of the cryogenic gas cooling provision; and the long-term performance of the integrated shell structure of the sensor-probe head. Of course, the overall reproducibility of the composition analysis data from individual immersion runs by the LPPSP system as deployed in steelmaking facilities is of great interest.

The process of selecting the host sites has been 
exceptionally slow and time consuming. The reasons are complex because the deployment can potentially impact the production schedules of a large manufacturing organization. They are thus partly technical and partly financial and legal in nature. The bridging step taken for trial immersions at a foundry has proven to be very beneficial in identifying the logistical and technical issues and developing the appropriate remedies. At present, the University and a specialty steelmaker are in the process of finalizing the deployment agreement.

Acknowledgement

The author acknowledges the valuable contributions of many past and present members of the project team at Lehigh University: C.S. Park, S.H. Kim, C. Lloyd-Knight and J.C. Oh; G. Brown, J. Labenski and J. Gregoris; R. Wolfinger, J. Zelinski, and M. Rex, all of the Physics Department. The encouragement and numerous technical assistances by the various representatives of the CTU 5-2 Committee, as chaired by F. Achey, D. Samson and currently by D. Reinbold, and the unrelenting championing of the project by the leadership of the American Iron and Steel Institute, including W.E. Dennis, B. Green, J. Farley and L. Kavanagh, have been essential to the long sustained march toward the success of the project. The support of $\mathrm{w}$. Obenchain of DOE-Washington and $\mathrm{R}$. Trimberger of DOE-Idaho and the assistance with various reports by J. Anderson and B. Brown of the Idaho National Engineering Laboratory have been invaluable. The patient support and 
facilitating provided by the officers and research administration staff members of Lehigh University are also acknowledged. Funding by the U.S. Department of Energy through the Metals Initiative, American Iron and Steel Institute, Lehigh University and CTU 5-2 Consortium is gratefully acknowledged. The author's words of appreciation are also extended to those steelmakers who have the courage and foresight to be part of the LPPSPS deployment process. Bailey Engineers has provided the valuable assistance in developing the dialogs with many steelmakers. Finally, the author expresses the generous hospitality of the foundry that has made its hot metal facilities available for immersion test runs with the second-generation LPPSP system. 